Cahiers $d u$ MONDE RUSSE

\section{Cahiers du monde russe}

Russie - Empire russe - Union soviétique et États indépendants

$43 / 4 \mid 2002$

Intellectuels et intelligentsia

\title{
Laura Ronchi De Michelis, Eresia e Riforma nel Cinquecento
}

\section{Valerio Marchetti}

\section{OpenEdition}

\section{Journals}

Édition électronique

URL : https://journals.openedition.org/monderusse/4006

DOI : 10.4000/monderusse.4006

ISSN : $1777-5388$

\section{Éditeur}

Éditions de l'EHESS

\section{Édition imprimée}

Date de publication : 30 décembre 2002

Pagination : 682-683

ISBN : 2-7132-1796-2

ISSN : $1252-6576$

Référence électronique

Valerio Marchetti, «Laura Ronchi De Michelis, Eresia e Riforma nel Cinquecento », Cahiers du monde russe [En ligne], 43/4 | 2002, mis en ligne le 17 juin 2009, consulté le 03 septembre 2022. URL : http:// journals.openedition.org/monderusse/4006; DOI : https://doi.org/10.4000/monderusse.4006

Ce document a été généré automatiquement le 3 septembre 2022.

Tous droits réservés 


\title{
Laura Ronchi De Michelis, Eresia e Riforma nel Cinquecento
}

\author{
Valerio Marchetti
}

\section{RÉFÉRENCE}

Laura RONCHI DE MICHELIS, Eresia e Riforma nel Cinquecento. La dissidenza

religiosa in Russia. Turin, Claudiana, 2000, $256 \mathrm{p}$.

1 Le protestantisme - par la simple proclamation d'un principe herméneutique (sola scriptura) qui soustrait le croyant à l'autorité interprétative d'une Église et à son magistère - a fait immédiatement émerger une multiplicité d'idées religieuses et un réseau de pratiques évangéliques qui tendaient à constituer une alternative aux institutions issues de la Réforme. C'est pour cela que l'on a introduit la notion de "réforme radicale»: celle-ci, au début, comprenait surtout des communautésqui s'étaient séparéesdes grandes églises protestantes etpratiquaient la morale évangélique, comme les anabaptistes, et des courants spiritualistes transversaux (dont G. H. Williams a donné la représentation la plus articulée et en même temps la plus synthétique dans Radical reformation, Philadelphie, 1961), mêlés à des individus réfractaires à tout lien ecclésiastique (les « hérétiques » de D. Cantimori, Eretici italiani del Cinquecento, Florence, 1939). La confessionnalisation a bloqué l'épanouissement du radicalisme, en ses formes les plus diverses, dans les pays qui avaient choisi le protestantisme selon les doctrines luthérienne et calviniste. Le déplacement de l'axe radical vers l'Europe orientale, où la formation de l'État moderne était moins avancée et la répartition des pouvoirs largement plus étendue, a permis, en Pologne et en Transylvanie, la constitution d'un système ecclésiastique "réformé " indépendant des structures luthériennes et calvinistes. Ce sont ceséglises radicalesqui ont hérité des plus importantes innovations théologiques introduites dans le christianisme au XVI ${ }^{\mathrm{e}}$ siècle, les ont développées, et, aux siècles suivants, ont donné à la pensée européenne un corpus d'idées susceptibles d'être élaborées ultérieurement. 
2 Le royaume de Pologne et le grand-duché de Lituanie ont offert un terrain fertile aux expérimentations théologiques les plus hardies qui ont conduit à l'affirmation de l'unitarianisme, c'est-à-dire à la restauration, par le biais de la critique antitrinitaire d'origine savante, du monothéisme dans le christianisme. Le problème posé par l'auteur est le suivant : que s'est-il passé en Russie - cette Russie orthodoxe qui avait à peine eu vent de la réforme protestante - à l'époque où les courants antitrinitaires bouleversaient le voisin royaume de Pologne, compte tenu du fait que, parmi les radicaux lituaniens, on trouvait des «moscovites » ? La réponse rejette nettement la ligne interprétative la plus répandue dans l'historiographie du XIX ${ }^{\mathrm{e}}$ siècle qui avait consacré au problème de l'hérésie à l'époque d'Ivan IV des travaux très importants (l'introduction de l'ouvrage en dresse un tableau exhaustif fort bien esquissé). Les documents conservés sur les grands procès qui se déroulèrent dans les années 1550 ne permettent pas de parler d'antitrinitarisme. Selon l'auteur, l'accusation est fabriquée par les autorités ecclésiastiques sur la base de quelques indices, assez flous, et n'apparaît explicitement que dans la sentence de condamnation. Les sources de l'hérésie des années 1550 sont donc à chercher ailleurs : dans la ligne qui part de Pskov et Novgorod, entre le XIve et le Xve siècle, et qui se joint à la préréforme européenne.

C'est seulement après avoir fui la Russieet émigré dans le territoire lituanien (p. 109-132), où la tendance la plus radicale du monothéisme était en cours de formation, qu'une partie des « hérétiques " russes (Kosoj, Ignatij) se sont liés à l'antitrinitarisme et ont rejoint l'unitarianisme (p. 133-204, voir l'analyse détaillée de la Poslanie mnogoslovnoe; l'Epistola Ioannis Smerae ; les Poslanija d'Artemij ; la Istiny pokazanie de Zonovij). C'est cette évolution doctrinale, attestée par une certaine quantité de documents mais probablement fort surévaluée, qui a permis aux érudits du XIX ${ }^{\mathrm{e}}$ siècle d'interpréter les actes des procès de Moscou à la lumière des mutations d'idées des protagonistes et de leur attribuer des doctrines qui, en réalité, sont survenues beaucoup plus tard. L'étude des sources des procès, de la personnalité des accusés (Baskin, Artemij, Viskovatyj) et des actes de procédure, constitue la partie la plus élaborée du livre (p.57-108). Elle est précédée d'un tableau essentiel de l'histoire de la Russie à partir de 1547, lorsque, après le couronnement d'Ivan IV, les rapports entre l'État et l'Église se complexifient et les relations internes à l'Église voient une lutte acharnée entre partisans d'une réforme de la vie chrétienne (chez les moines de la Russie septentrionale) et forces de résistance traditionnelles. 